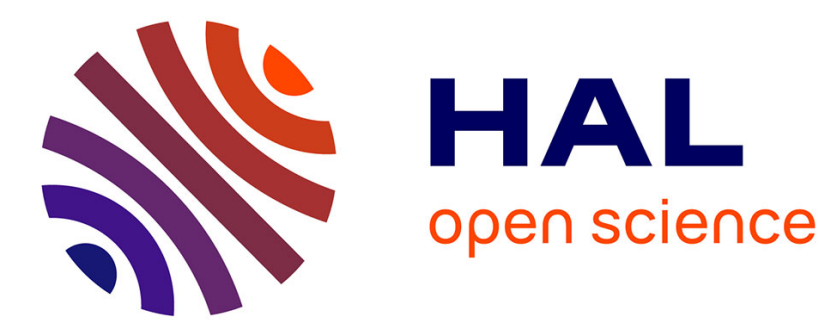

\title{
Transmission Electron Microscopy Studies of (AIN-Si3N4) Codeposits Obtained by LPCVD
}

\author{
P. Marti, F. Henry, Annie Mazel, B. Armas, Jean Sévely
}

\section{To cite this version:}

P. Marti, F. Henry, Annie Mazel, B. Armas, Jean Sévely. Transmission Electron Microscopy Studies of (AIN-Si3N4) Codeposits Obtained by LPCVD. Journal de Physique IV Proceedings, 1995, 05 (C5), pp.C5-905-C5-912. 10.1051/jphyscol:19955107 • jpa-00253774

\section{HAL Id: jpa-00253774 https://hal.science/jpa-00253774}

Submitted on 1 Jan 1995

HAL is a multi-disciplinary open access archive for the deposit and dissemination of scientific research documents, whether they are published or not. The documents may come from teaching and research institutions in France or abroad, or from public or private research centers.
L'archive ouverte pluridisciplinaire HAL, est destinée au dépôt et à la diffusion de documents scientifiques de niveau recherche, publiés ou non, émanant des établissements d'enseignement et de recherche français ou étrangers, des laboratoires publics ou privés. 
JOURNAL DE PHYSIQUE IV

Colloque C5, supplément au Journal de Physique II, Volume 5, juin 1995

\title{
Transmission Electron Microscopy Studies of (AlN-Si3N4) Codeposits Obtained by LPCVD
}

\author{
P. Marti, F. Henry*, A. Mazel, B. Armas* and J. Sevely \\ CEMES-LOE/CNRS, BP. 4347, 31055 Toulouse cedex, France \\ * IMP/CNRS, BP. 5, Odeillo, 66125 Font-Romeu cedex, France
}

\begin{abstract}
Several (Al,Si,N) compounds have been obtained by LPCVD in a vertical hot-wall reactor using aluminium trichloride, silicon tetrachloride and ammonia as source gases, with nitrogen as the carrier gas. In order to determine both their structure and local chemical composition, several deposits have been examined by analytical transmission electron microscopy combining electron diffraction (ED), high resolution electron microscopy (HREM) and electron energy loss spectroscopy (EELS). It has been confirmed that the chemical composition of the materials as well as the size of the "nanocrystals" observed in the deposits are strongly dependent on the temperature and the reactive gas flow. It has also been shown that for the range of temperature $(1273 \mathrm{~K}-1373 \mathrm{~K})$ used in this work these "nanocrystals" have the wurtzite structure of aluminium nitride.
\end{abstract}

\section{INTRODUCTION}

Among the many nitride ceramics, aluminium and silicon nitride are of considerable interest owing to their potential use for high temperature and electronic applications. In order to obtain materials having better properties than those of AlN or $\mathrm{Si}_{3} \mathrm{~N}_{4}$ alone, particularly concerning their oxidation behaviour, the Al-Si-N system has been studied. The mixed deposition of aluminium and silicon nitride on silicon and sapphire substrates has been investigated by Zirinski [1] using ammonialysis of aluminium trichloride and silane. The phase equilibrium of this system has been established by Weitzer and al. [2]. From their results it can be concluded that neither a ternary compound nor a solid solution can be formed.

The simultaneous synthesis of AIN and $\mathrm{Si}_{3} \mathrm{~N}_{4}$ has been achieved by chemical vapour deposition with aluminium trichloride, silicon tetrachloride and ammonia as precursors. A preliminary thermodynamic study [3] has shown that the formation of $\mathrm{AlN}-\mathrm{Si}_{3} \mathrm{~N}_{4}$ codeposits requires a high molar ratio of $\mathrm{NH}_{3} /\left(\mathrm{AlCl}_{3}+\mathrm{SiCl}_{4}\right)$. The physical properties of the materials are strongly dependent on their microstructure and thus on their processing parameters. A study of the structure and surface morphology of the deposits has been made by $\mathrm{X}$-ray diffraction and scanning electron microscopy [4]. Current analytical transmission electron microscopy techniques allow us to obtain structural and chemical information at high spatial resolution. These methods have been employed to investigate the influence of the experimental conditions on the composition and microstructure of various deposits.

\section{EXPERIMENTAL PROCEDURE}

\subsection{Elaboration of the deposits}

The experimental system used was a vertical hot-wall reactor composed of a graphite susceptor heated by high-frequency induction. The source gases were aluminium trichloride $\mathrm{AlCl}_{3}$, silicon tetrachloride $\mathrm{SiCl}_{4}$, ammonia $\mathrm{NH}_{3}$ and nitrogen $\mathrm{N}_{2}$ as a carrier gas. The $\mathrm{AlCl}_{3}$ was obtained by chemical reaction between gaseous $\mathrm{SiCl}_{4}$ and a metallic aluminium supply heated to a temperature $\mathrm{T}_{\mathrm{c}}$, in the range from $650 \mathrm{~K}$ to $790 \mathrm{~K}$ [5]. The silicon tetrachloride $\mathrm{SiCl}_{4}$ contained in an evaporator was heated to $313 \mathrm{~K}$ (vapour pressure $\sim 54.10^{3} \mathrm{~Pa}$ ). All gas connections were thermally insulated to prevent any condensation. The ammonia was injected separately from the other reactive gases to avoid reaction outside the reaction 
zone. A graphite base covered by a $\mathrm{SiC}$ layer produced by pyrolysis of tetramethylsilane was used as a substrate for all deposits.

The elaboration process was carried out under the following conditions : pressure $133 \mathrm{~Pa}$, reactor temperature $1273 \mathrm{~K}$ to $1373 \mathrm{~K}, \mathrm{~N}_{2}$ flow rate $10^{-3} \mathrm{~cm}^{3} \cdot \mathrm{h}^{-1}$, and gas phase composition depending on the value of $T_{c}[5]$.

\subsection{Analytical transmission electron microscopy}

The deposits have been examined by complementary transmission electron microscopy techniques including conventional microscopy (in bright-field and dark-field), electron diffraction (ED), High Resolution Electron Microscopy (HREM) and Electron Energy Loss Spectroscopy (EELS). Thin specimens suitable for electron microscopy were prepared by mechanical polishing followed by $\mathrm{Ar}^{+}$ion milling. The experiments have been performed with a Philips CM30ST microscope operating at $300 \mathrm{kV}$ (point resolution close to $0.2 \mathrm{~nm}$ ) with direct magnification up to $10^{6}$ and an objective aperture radius corresponding to spatial frequencies down to $7 \mathrm{~nm}^{-1}$. The interpretation of the HREM images is based on comparison with simulations. The latter have been made using the multislice method (MacTempas program) [6] with spherical aberration $1.2 \mathrm{~mm}$, rms defocus spread $8 \mathrm{~nm}$, semi-angle of beam convergence 1.2 mrad and assuming a rms mechanical vibration of about $0.02 \mathrm{~nm}$.

For EELS experiments, an on-line Gatan 666 parallel spectrometer with a typical resolution of $1.5 \mathrm{eV}$ (full width at half maximum of the zero-loss peak) was used. The samples have been studied from the chemical point of view by considering electron energy losses associated both with plasmons and atomic inner-shell excitations. The acquisition steps of the spectra were chosen to be $0.1 \mathrm{eV}$ and $1 \mathrm{eV}$ for plasmons and inner-shell edges respectively. The value of the semi-angle of collection was $7.5 \mathrm{mrad}$ and the spatial resolution was in the range $10 \mathrm{~nm}-80 \mathrm{~nm}$. The standard quantitative treatment of the spectra, as proposed by Egerton [7], allowed us to obtain the atomic concentration ratios from the K-edges corresponding to the different elements present in the material.

\section{RESULTS AND DISCUSSION}

Three kinds of deposits have been analysed. The conditions of the elaboration process and the concentration ratios of the various elements determined by wavelength-dispersive spectroscopy (WDS) are listed on table 1.

Table 1 : Experimental conditions of the elaboration process and macroscopic chemical composition of the (Al-Si-N) compounds.

\begin{tabular}{|c|c|c|c|}
\hline Sample & 1 & 2 & 3 \\
\hline $\begin{array}{c}\text { Reactor } \\
\text { Temperature }\end{array}$ & $1373 \mathrm{~K}$ & $1373 \mathrm{~K}$ & $1273 \mathrm{~K}$ \\
\hline $\mathrm{T}_{\mathrm{c}}$ & $711 \mathrm{~K}$ & $732 \mathrm{~K}$ & $745 \mathrm{~K}$ \\
\hline Macroscopic & $\mathrm{Al} / \mathrm{N}=0.25$ & $\mathrm{Al} / \mathrm{N}=0.43$ & $\mathrm{Al} / \mathrm{N}=1.01$ \\
Chemical & $\mathrm{Si} / \mathrm{N}=0.52$ & $\mathrm{Si} / \mathrm{N}=0.40$ & $\mathrm{Si} / \mathrm{N}=0.14$ \\
Composition & $\mathrm{O} / \mathrm{N}=0.07$ & $\mathrm{O} / \mathrm{N}=0.02$ & $\mathrm{O} / \mathrm{N}=0.04$ \\
(WDS) &
\end{tabular}

\subsection{Sample 1}

This sample has been obtained for a relatively low value of the temperature $T_{c}$ of the aluminium supply so that only a small amount of aluminium is expected to be present in the deposit. This is confirmed by the chemical composition determined by WDS (table 1).

As deduced from the broad and diffuse ring observed on the diffraction pattern of Fig. 1(a), this material appears to be amorphous. This is clearly visible on the centred dark-field image obtained by selecting with the objective aperture a small part of the ring. The size of the bright dots (about $0.5 \mathrm{~nm}$ ) is in good agreement with the value estimated from the width of the diffraction ring. 
Given the homogeneous appearance of the deposit, the EELS chemical analysis has been performed with a relatively large probe size $(80 \mathrm{~nm})$. The electron energy loss spectra reproduced on Fig. 1(b) show the K-edges associated with nitrogen $(401 \mathrm{eV})$, oxygen $(532 \mathrm{eV})$, aluminium $(1560 \mathrm{eV})$ and silicon $(1840 \mathrm{eV})$. The corresponding plasmon energy loss was found to be $22.8 \mathrm{eV}$. This value is halfway between those corresponding to crystallised aluminium nitride $(21.7 \mathrm{eV})$ and silicon nitride $(23.8 \mathrm{eV})$ [8]. The chemical composition deduced from the treatment of these spectra shows that the amount of silicon is about twice that of aluminium. This is consistent with the concentration ratios determined at a macroscopic scale for the bulk material (cf table 1). All these results indicate that the material consists of a mixture of amorphous silicon nitride and aluminium nitride.

\subsection{Sample 2}

The diffraction ring pattern shown in Fig. 2(a) reveals that this material, obtained for a higher value of $\mathrm{T}_{c}$, is more crystallised than the first. The sample is composed of "nanocrystals", the average size of which is about $5 \mathrm{~nm}$. They can be seen on the centred dark-field image obtained by selecting a small part of the "first ring" (in fact it corresponds to three rings which cannot be distinguished here). The inter-reticular distances estimated from the radii of the diffraction rings are close to those of the aluminium nitride structure.

Chemical analysis of a single crystal and of the surrounding amorphous areas was impossible because of their dimensions so the same large probe $(80 \mathrm{~nm})$ was used as in the case of sample 1 . The quantitative treatment of the spectra reproduced on Fig. 2(b) yields an atomic concentration ratio Si/Al close to 1. This result is in good agreement with the values obtained by WDS. For this sample, the plasmon energy loss was found to be $22.6 \mathrm{eV}$.

In order to determine more precisely the structure of the "nanocrystals", the sample was observed in plane view at high resolution. An example of an axial-illumination bright-field HREM image of a thin region is shown on Fig. 3(a). Some periodic atomic arrangements, corresponding to different orientations of the "nanocrystals", can be seen. Enlargements of the encircled zone obtained for different defocus values are reproduced on Fig. 3(b). The inserted simulations have been calculated for an aluminium nitride layer ( $3 \mathrm{~nm}$ thick) observed in the [001] orientation. A Debye temperature of $950 \mathrm{~K}$ has been considered in the calculations [9]. The good match between these simulations and the experimental images confirms that the "nanocrystals" have the wurtzite structure $(2 \mathrm{H})$ of AlN. Depending on the defocus value, the atomic columns appear black or white as shown by the associated projected potential maps.

Figure 4 is another example of a HREM image obtained from a cross-section of sample 2 . It exhibits a cluster consisting of several crystals larger than those previously seen. They are observed along the [110] direction which allows us, in the case of the $2 \mathrm{H}$ wurtzite structure, to visualize the stacking sequence of the layers and consequently to identify this structure clearly. There is good agreement between an image calculated for this incident electron beam direction and the experimental one. This again demonstrates that the "nanocrystals" observed in the deposit are constituted by aluminium nitride. Considering the amount of silicon found in the material and the relatively low elaboration temperature, the amorphous regions surrounding the AlN crystals are expected to be mainly silicon nitride.

\subsection{Sample 3}

This last sample has been obtained for a high value of $\mathrm{T}_{\mathrm{c}}$ (table 1) which implies that there is more $\mathrm{AlCl}_{3}$ in the gas mixture. Consequently, the amount of aluminium nitride in the deposit should be greater than for the other samples leading to a material more highly crystallised.

TEM observations of a cross-section of this sample confirm that it was actually polycrystalline, the size of the crystals increasing from the substrate up to the surface of the deposit. However, a thin layer of small crystals has been found on the top of the deposit. They appear with dark contrast (region (a)) on the bright field micrograph of a plane-view of the sample shown Fig. 5(a) next to large bright crystals (region (b)) located just below the previous ones. The former gives rise to fine rings in the inset selected-area diffraction pattern as confirmed by the centred dark-field image reproduced on Fig. 5(b). The mean size of these crystals is about $20 \mathrm{~nm}$. As for sample 2, the d-spacings deduced from the radii of the diffraction rings agree well with those corresponding to aluminium nitride.

Chemical analyses have been performed with the same probe size $(60 \mathrm{~nm})$ at different levels in the deposit near the interface with the silicon carbide layer. It has been found that the atomic concentration of silicon increases with proximity to this interface ( $\mathrm{Si} / \mathrm{Al}$ up to 0.4 ). This could be related to preferential growth of silicon nitride at the beginning of the process. The amount of silicon detected at the top of the deposit would then be lower. The quantitative treatment of the spectra (Fig. 6) obtained from both kinds of crystals (a) and (b) observed at the top of the deposit with an appropriate probe size $(30 \mathrm{~nm})$ confirms this 
result. It yields atomic concentration ratios for $\mathrm{Si} / \mathrm{Al}$ of about 0.08 and for $\mathrm{Al} / \mathrm{N}$ close to unity. The corresponding plasmon energy loss is close to $21.7 \mathrm{eV}$. This value corresponds to stoichiometric aluminium nitride [8]. Both crystals therefore appear to be aluminium nitride.

Axial bright-field HREM images of the two kinds of crystals (a) and (b) observed along the [001] direction are presented on Fig. 7 and Fig. 8 respectively. The different contrasts appearing on the image of a crystal (a) (Fig. 7) have been related to thickness and orientation variations as shown by the inserted simulations. In the case of crystal (b), HREM images have been obtained for two defocus values corresponding to minimum contrast and Scherzer defocus (Fig. 8). The good match between the different simulations and the experimental images confirms that the atomic arrangements do indeed correspond in both cases to aluminium nitride crystals, despite the significant amount of silicon detected by EELS chemical analyses. The presence of silicon could be related to a thin amorphous layer of silicon nitride surrounding the AlN crystals. However, as noted by Slack and Kelly [10], silicon should also be considered as possible substituent for aluminium in the Al sublattice of AlN. No experimental evidence for this last assumption has been obtained by HREM imaging. Aluminium and silicon do indeed have very close $\mathrm{Z}$ atomic numbers so the HREM images calculated from a structure including substituted silicon cannot be distinguished from those corresponding to stoichiometric aluminium nitride.

\section{Conclusion}

Analytical electron microscopy studies have been carried out on deposits containing aluminium, silicon and nitrogen. The compositional and microstructural changes of the compounds have been related to their experimental conditions of preparation. It has been established that, in addition to the deposition temperature of the samples, the temperature of the aluminium supply, $\mathrm{T}_{\mathrm{C}}$, plays an important role in determining the composition of the deposits. It was observed that, as the temperature $T_{c}$ was increased, the amount of aluminium in the deposit increased at the expense of the quantity of silicon. This leads to a progressive increase in the degree of crystallinity of the materials. The structure of the crystals has been identified by HREM imaging as that of aluminium nitride.

Chemical analyses have been performed at a nanometric scale by electron energy loss spectroscopy. For all the deposits, the atomic concentration ratios deduced from the quantitative treatment of the EELS spectra are very close to the values determined by wavelength-dispersive spectroscopy (WDS) at a macroscopic scale for the bulk materials. More accurate analyses of EXELFS type (Extended Energy Loss Fine Structure) are planned in order to determine the local atomic environment of silicon in the materials and hence confirm the presence of amorphous silicon nitride phase.

In conclusion, the results presented in this paper illustrate the various possibilities of HREM combined with EELS for studying the nanostructure and the chemical composition of a wide range of materials at the atomic level. These methods of analysis are particularly well adapted to materials consisting of light elements, which is the case for most of the ceramics being now considered for specific applications at high temperature.

\section{Acknowledgements}

This work has been partially supported by the French Ministry of Defense, Direction des Recherches et Etudes Techniques (Contrat DRET N ${ }^{\circ} 9011$ 97A).

\section{References}

[1] Zirinski S., Irene E. E., J. Electrochem. Soc., 125 (2) (1978) 305-314.

[2] Weitzer F., Remschnig K., Schuster J.C., Rogl P., J. Mater. Res., 8 (10) (1990) 2152-2159.

[3] Henry F., Armas B., Balat M., Berjoan R., Combescure C., J. Physique IV, C3, Suppl II, 3 (1993) 519-526.

[4] Henry F., Thesis, Université de Montpellier II (1995).

[5] Henry F., Armas B., Combescure C., Flamand R. (This conference).

[6] O'Keefe M. A., Kilaas R., Scanning Microscopy Supplement 2 (1988) 225-244.

[7] Egerton R.F. Electron Energy Loss Spectroscopy in the Electron Microscope (Plenum Press, New York, 1986).

[8] Kihn Y.Private communication.

[9] Slack G.A., J. Phys. Chem. Solids, 34 (1973) 321-335.

[10] Slack G.A., McNelly T.F., J. Crystal Growth 34 (1976) 263-279. 

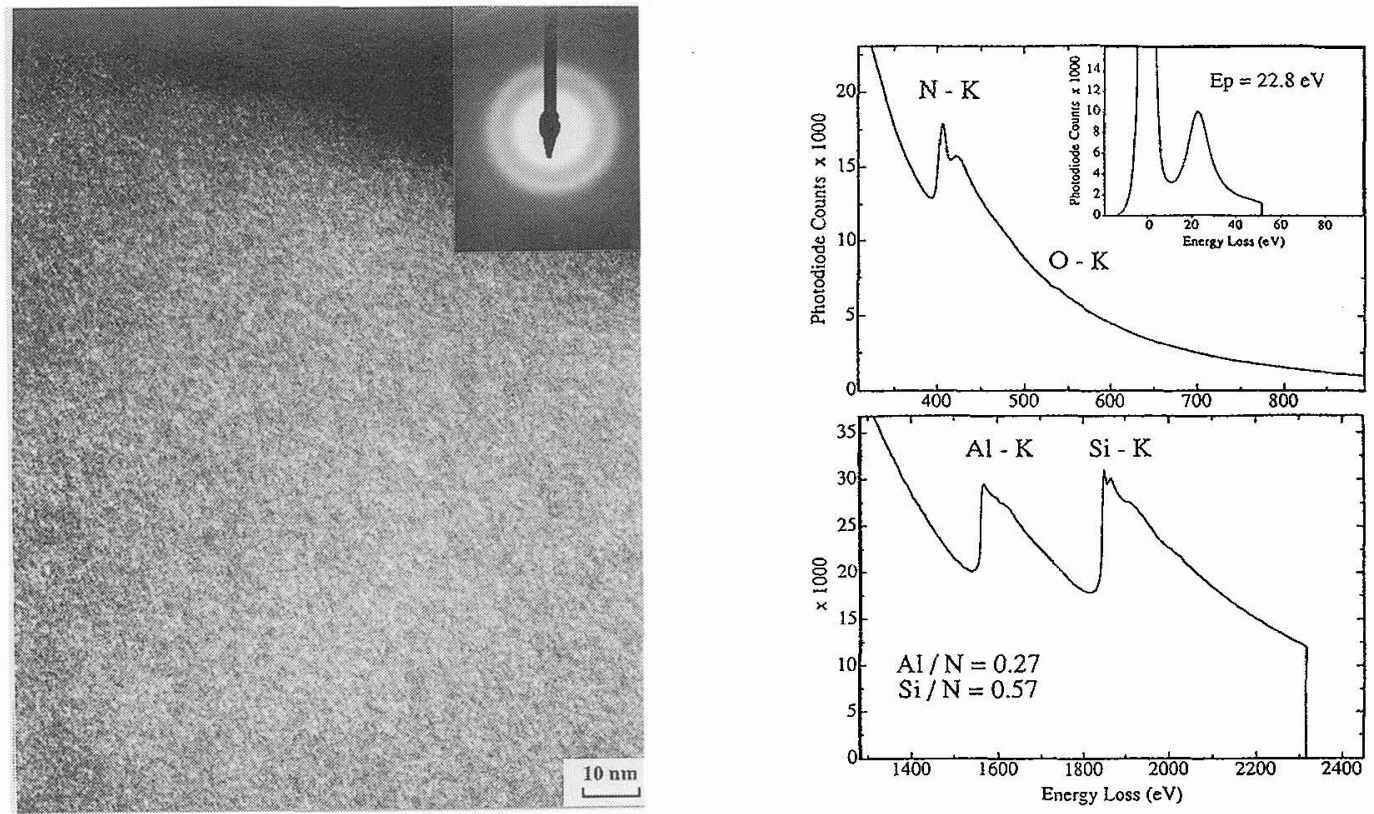

(b)

Figure 1 : (a) Centred dark-field image of sample 1 and associated diffraction pattern (b) Examples of corresponding electron energy loss spectra.
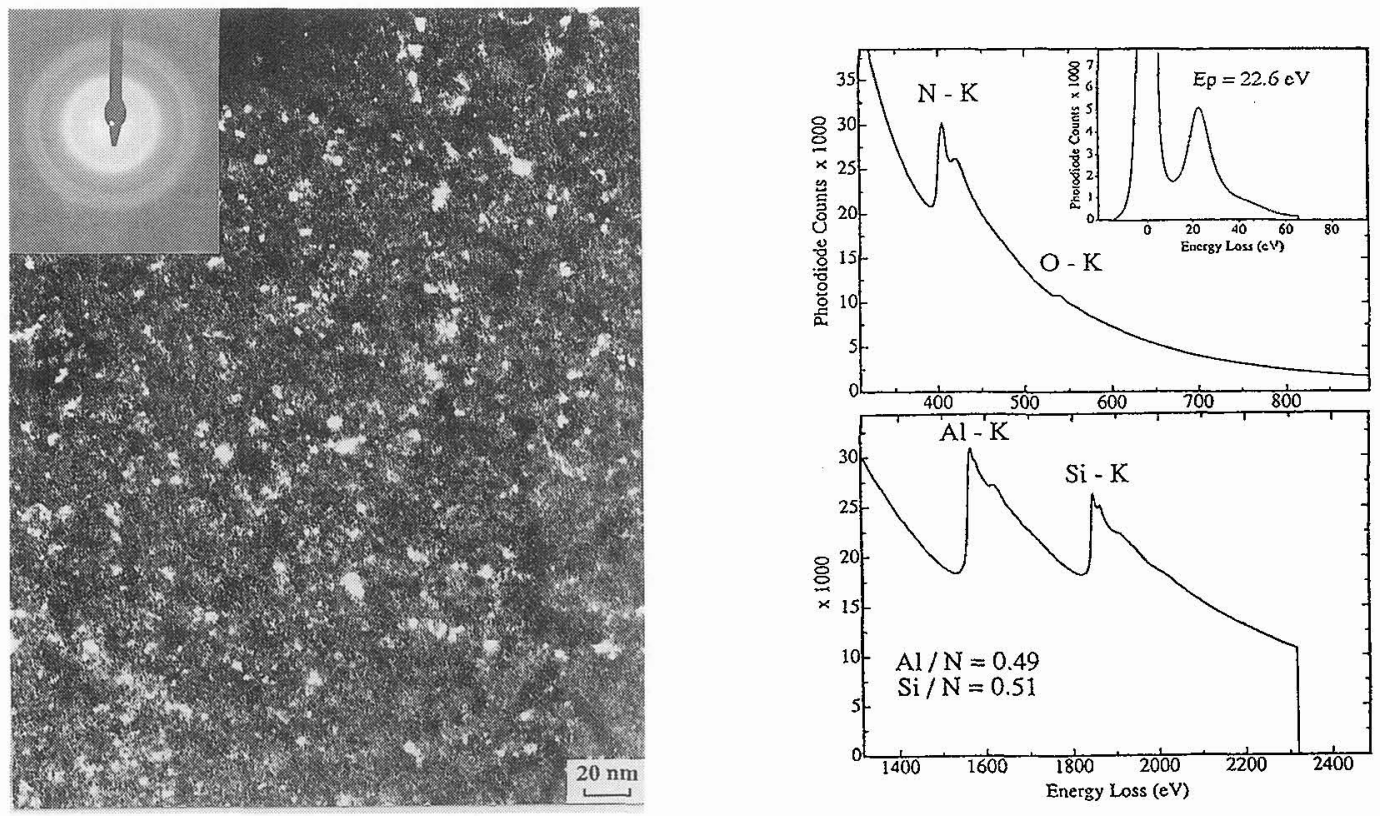

(b)

Figure 2 : (a) Centred dark-field image of sample 2 and associated diffraction pattern (b) Examples of corresponding electron energy loss spectra. 


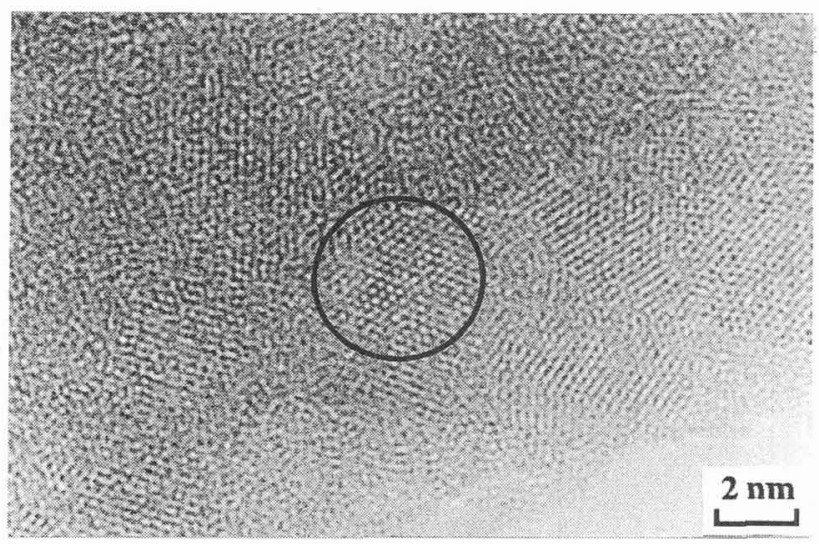

Figure 3 (a) : Axial-illumination bright- field HREM image of sample 2 showing periodic atomic arrangements related to "nanocrystals".
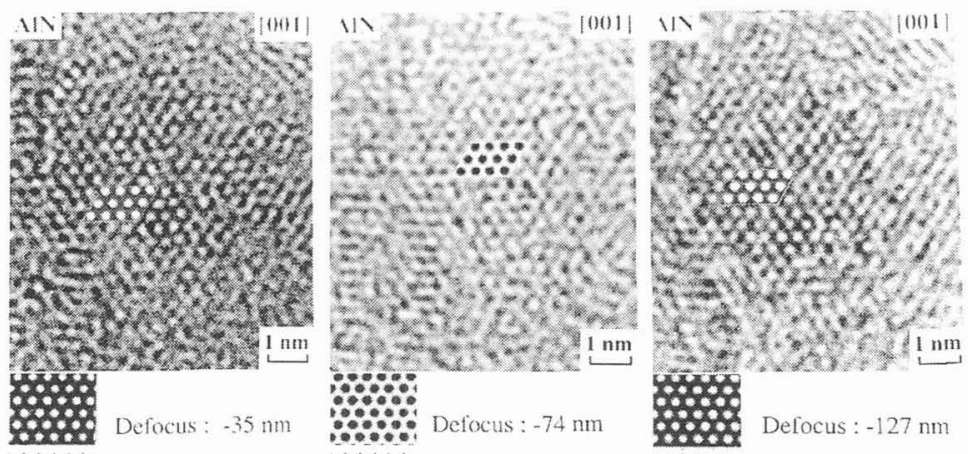

Figure 3 (b) : Enlargements of the encircled zone corresponding to different defocus values. Depending on this value, the atoms appear dark or white as shown by the associated projected potential map (thickness : $3 \mathrm{~nm}$, beam direction [001]).

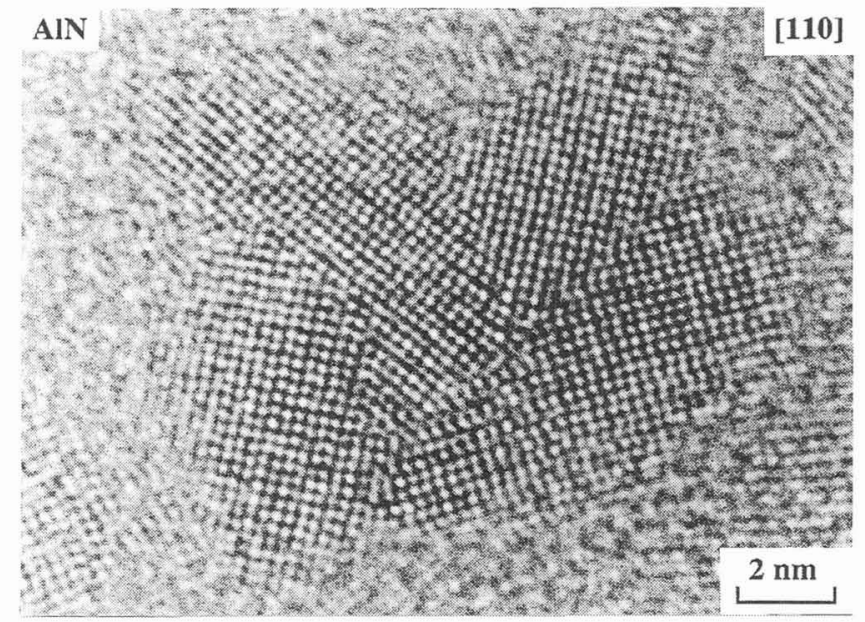

Figure 4 : Another example of a HREM image of sample 2 showing several crystals of larger size observed along the [110] direction ( thickness : $4 \mathrm{~nm}$, defocus : $-75 \mathrm{~nm}$, "white" atoms). 


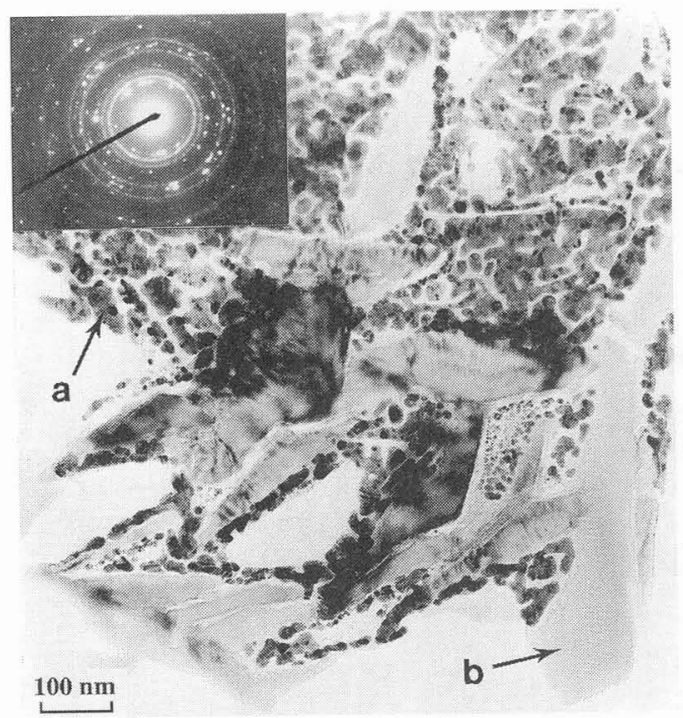

(a)

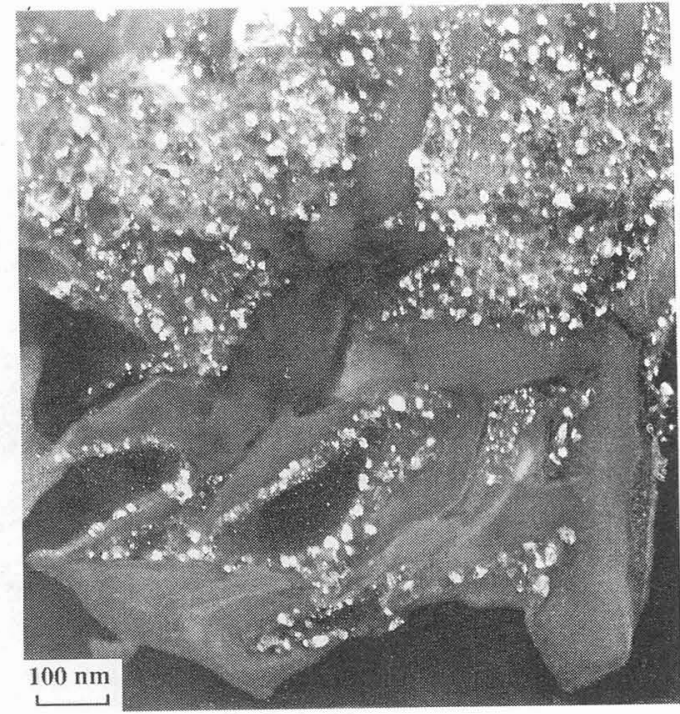

(b)

Figure 5 : (a) Bright-field image of sample 3 and associated diffraction pattern (b) Centred dark-field image obtained by selecting a small part of the first three rings.
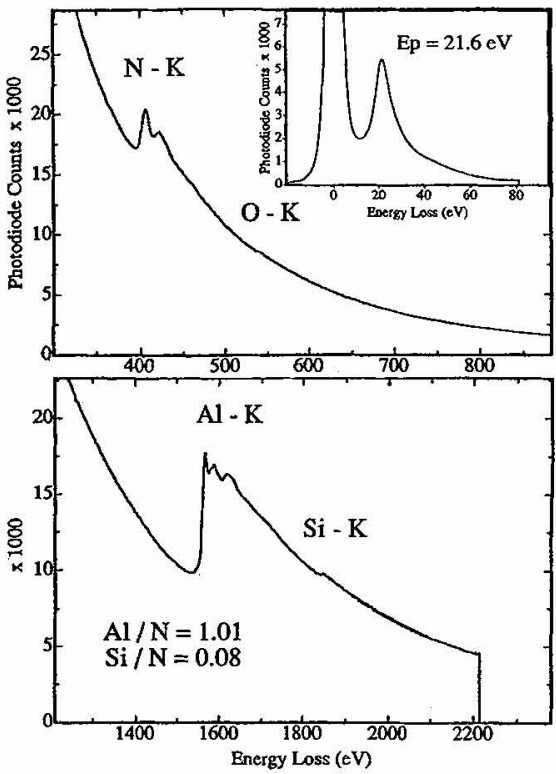

(a)

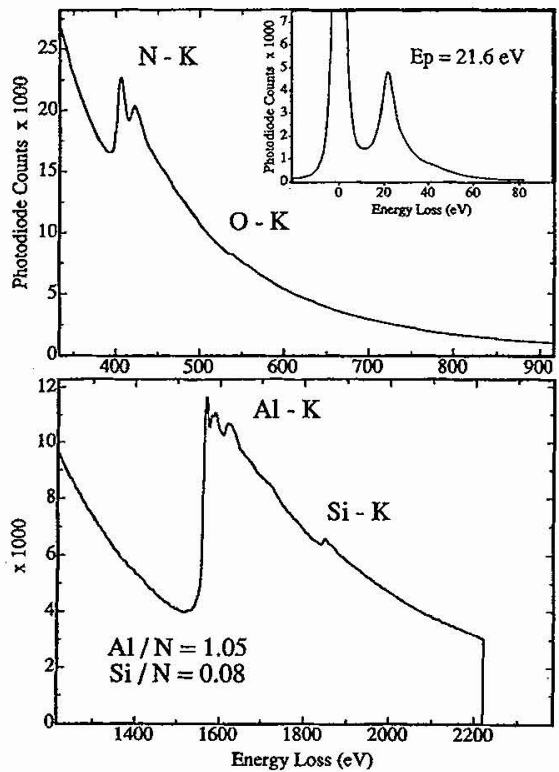

(b)

Figure 6 : Examples of electron energy loss spectra corresponding to : (a) a small crystal (region (a)) ; (b) a large bright crystal (region (b)). 


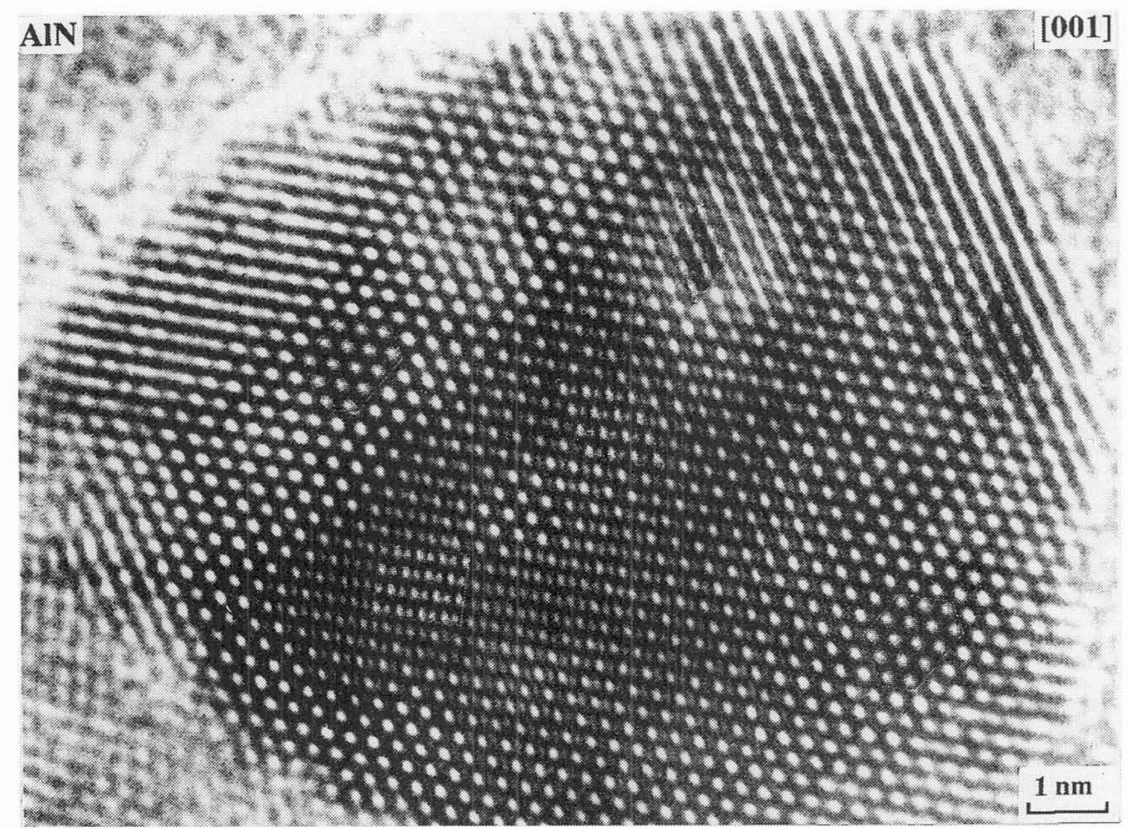

Figure 7 : High resolution bright-field image of a "nanocrystal" of region (a) (observation direction [001]) showing contrast variations with thickness and orientation and associated simulations (defocus : $-48 \mathrm{~nm}$ ).
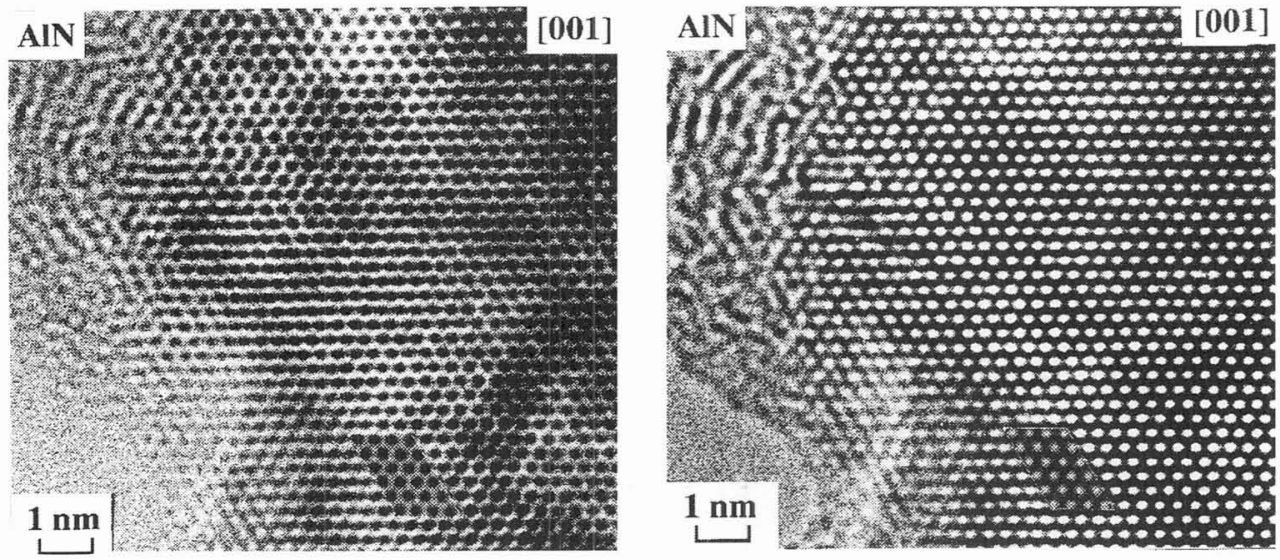

Figure 8 : HREM images of a large crystal of region (b) observed along the [001] direction. The inset simulations have been calculated for two defocus values corresponding to the minimum of contrast (defocus : $-23 \mathrm{~nm}$; "white" atoms) and to Scherzer defocus (defocus : $-60 \mathrm{~nm}$; "black" atoms) respectively (crystal thickness : $3 \mathrm{~nm}$ ). 